\title{
Synthesis and Evaluation of Olivine Nanosheets from Layered Ammonium Iron Phosphate Monohydrate
}

\author{
Masakazu Togo and Atsushi Nakahira* \\ Department of Materials Science, Graduate School of Engineering, Osaka Prefecture University, 1-1 Gakuen-cho, Nakaku, Sakai, Osaka 599-8531, Japan
}

\begin{abstract}
The synthesis of novel microstructured $\mathrm{LiFePO}_{4}$ with advantageous nanosheets for Li ion conductivity was attempted. Using layered $\mathrm{NH}_{4} \mathrm{FePO}_{4} \cdot \mathrm{H}_{2} \mathrm{O}$ as raw material, $\mathrm{LiFePO}_{4}$ nanosheet was synthesized by the hydrothermal process in $\mathrm{LiCl}$ solution. Prepared $\mathrm{NH}_{4} \mathrm{FePO}_{4} \cdot \mathrm{H}_{2} \mathrm{O}$ was several tens micrometer sized sheet with about $200 \mathrm{~nm}$ in thickness. As $\mathrm{Li}$ ion resource, various $\mathrm{LiCl}$ solution like deionized water, ethanol, and ethylene glycol were prepared through subsequent hydrothermal process and the effect of a kind of solvents for $\mathrm{LiCl}$ solution on the microstructure

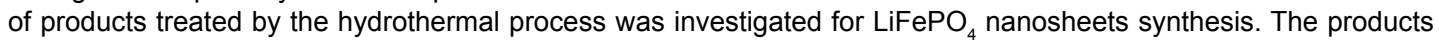
of $\mathrm{LiFePO}_{4}$ nanosheet were characterized by XRD, SEM, TEM, FT-IR and ICP. Regardless of a kind of solvents, $\mathrm{LiFePO}_{4}$ nanosheet was composed of arranged nano-blocks, although the size and morphology of nano-blocks was different in each solvent.
\end{abstract}

Keywords: Lithium iron phosphate; Nano material; Hydrothermal synthesis

\section{Introduction}

In order to put the sustainable society into practice, environmentfriendly material has been taken strong interest in. Lithium iron phosphate as the material not using rare metal like cobalt, $\mathrm{LiFePO}_{4}$, has the characters like the plateau redox potential, the good cycle performance and the unique stability, compared to other materials like $\mathrm{LiCoO}_{2}$. $\mathrm{LiFePO}_{4}$ shows $3.5 \mathrm{~V}$ vs. Li of redox potential and $170 \mathrm{mAhg}^{-1}$ of theoretical capacity. The discharge reaction of $\mathrm{LiFePO}_{4}$ is showed in the following equation.

\section{$\mathrm{LiFePO}_{4} \rightarrow \mathrm{Li}_{1-x} \mathrm{FePO}_{4}+x \mathrm{Li}^{+}+x \mathrm{e}$}

$\mathrm{LiFePO}_{4}$ has olivine-type structure and belongs to poly-anion group [1]. Olivine-type material, that composition expressed in $\mathrm{LiMePO}$ $(\mathrm{Me}=\mathrm{Fe}, \mathrm{Mn}, \mathrm{Co} . \mathrm{Ni})$, is composed of edge-shearing $\mathrm{PO}_{4}$ tetrahedral and $\mathrm{MeO}_{6}$ octahedral. $\mathrm{LiMnPO}_{4}$ has $4.1 \mathrm{~V}$ vs. Li higher potential than that of $\mathrm{LiFePO}_{4}$ [2]. Some groups researched $\mathrm{LiMn}_{x} \mathrm{Fe}_{1-x} \mathrm{PO}_{4}$ of having two-plateau potential [3-5]. The more energy density than that of single composition $\mathrm{LiFePO}_{4}$ would be expected.

On the other hand, the conductivity is very small because olivinetype material is the ionic crystal of $\mathrm{XO}^{4-}$ and cations [6]. The material with more conductivity can shows the enough discharging capacity at high charging rate. Doping elements, composite with conductive material and morphology control had been investigated in order to improve the conductivity. Chung reported olivine material doped with the multi cation, such as $\mathrm{Mg}^{2+}, \mathrm{Al}^{3+}, \mathrm{Zr}^{4+}, \mathrm{Nb}^{5+}$ and $\mathrm{W}^{6+}$, had the good rate capability [7]. Also, for conductivity improvement, $\mathrm{LiFePO}_{4} / \mathrm{C}$ composite was produced by heating the mixture of the active material and lactose in inert atmosphere [8] and depositing carbon from heat decomposition of propylene gas [9]. With increasing the amount of the conductive additive, however, the active material density in electrode decreases. Therefore, the importance of nano-sized material increases for these $\mathrm{LiFePO}_{4}$ materials.

The nano-sized materials also grow in importance for positiveelectrode materials for lithium ion battery. If the electrode material makes a finer particle, its reactivity increases due to the improvement of the specific surface area. In addition, the ion diffusion length for nano-sized materials is short, and this is quietly advantageous to battery materials. In addition, for the electrode material, morphology is also the important factor for improvements in the reactivity and cycle performance as well as the particle size. Many studies on $\mathrm{LiFePO}_{4}$ synthesis by hydrothermal reaction has been reported [10-12], and the morphology and particle size are well-known to be affected under synthetic parameters such as $\mathrm{pH}$ of reaction solution, reaction temperature, and reaction time. $\mathrm{LiFePO}_{4}$ has one-dimensional $\mathrm{Li}^{+}$ conduction pass, and the domino-cascade conduction model was suggested [13]. Therefore, recently the platelet/sheet structured $\mathrm{LiFePO}_{4}$ materials have attracted much attention for use of more efficient to $\mathrm{Li}^{+}$ conduction. Zhao reported about $\mathrm{LiFePO}_{4}$ nanosheets synthesis and electrical property [14]. They obtained $\mathrm{LiFePO}_{4}$ nanosheets by the exfoliation of bulk $\mathrm{LiFePO}_{4}$ powders.

In recent decades, many attempts for nanosheets synthesis had been also reported using layered oxide compounds such as $\mathrm{TiO}_{2}, \mathrm{MnO}_{2}$, and $\mathrm{Nb}_{2} \mathrm{O}_{5}$ [15-17]. Mostly, it is reported that various nanosheets are obtained by the exfoliation of layered compound. Layered ammonium iron phosphate monohydrate, $\mathrm{NH}_{4} \mathrm{FePO}_{4} \cdot \mathrm{H}_{2} \mathrm{O}$, was synthesized by hydrothermal process as a starting material for nanosheets and then $\mathrm{LiFePO}_{4}$ sheets was exfoliated by the subsequent hydrothermal reaction for this layered $\mathrm{NH}_{4} \mathrm{FePO}_{4} \cdot \mathrm{H}_{2} \mathrm{O}$ in $\mathrm{Li}$ solution. The synthesis condition of $\mathrm{LiFePO}_{4}$ nanosheets was investigated by hydrothermal process and the microstructure were evaluated.

\section{Materials and Methods}

\section{Preparation of layered $\mathrm{NH}_{4} \mathrm{FePO}_{4} \cdot \mathrm{H}_{2} \mathrm{O}$}

Layered $\mathrm{NH}_{4} \mathrm{FePO}_{4}$ was prepared by hydrothermal process. As

*Corresponding author: Atsushi Nakahira, Department of Materials Science Graduate School of Engineering, Osaka Prefecture University, 1-1 Gakuen-cho, Nakaku, Sakai, Osaka 599-8531, Japan, Tel: 072-254-9315; Fax: 072-254-9912; E-mail: nakahira@mtr.osakafu-u.ac.jp

Received November 27, 2017; Accepted November 29, 2017; Published December 10, 2017

Citation: Togo M, Nakahira A (2017) Synthesis and Evaluation of Olivine Nanosheets from Layered Ammonium Iron Phosphate Monohydrate. J Material Sci Eng 6: 403. doi: 10.4172/2169-0022.1000403

Copyright: $\odot 2017$ Togo M, et al. This is an open-access article distributed under the terms of the Creative Commons Attribution License, which permits unrestricted use, distribution, and reproduction in any medium, provided the original author and source are credited. 
reaction solution, $0.5 \mathrm{M} \mathrm{FeSO}_{4}$ solution and $0.5 \mathrm{M} \mathrm{NH}_{4} \mathrm{H}_{2} \mathrm{PO}_{4}$ solution were prepared. Fe resources were added in $\mathrm{P}$ resources with an equal molar ratio, and the $\mathrm{pH}$ of mixed solution was maintained at $\mathrm{pH} 10$ by adding aqueous ammonia. Then, the result solution was transferred in Teflon vessels, and they were kept at $150^{\circ} \mathrm{C}$ for 24 hours. The products were filtrated, washed, and dried at $50^{\circ} \mathrm{C}$ overnight.

\section{Synthesis $\mathrm{LiFePO}_{4}$ nanosheets from layered $\mathrm{NH}_{4} \mathrm{FePO}_{4} \bullet \mathrm{H}_{2} \mathrm{O}$ compounds}

Obtained $\mathrm{NH}_{4} \mathrm{FePO}_{4}$ was used as raw material for nanosheets. $\mathrm{LiCl}$ as lithium resource was dissolved in each solvent, such as deionized water, ethanol, and ethylene glycol. Effect of a kind of solvents for $\mathrm{LiCl}$ solution on the microstructure of products treated by the subsequent hydrothermal process was investigated for $\mathrm{LiFePO}_{4}$ nanosheets synthesis. $0.5 \mathrm{~g}$ of $\mathrm{NH}_{4} \mathrm{FePO}_{4}$ was added in $\mathrm{LiCl}$ solution. Mixed solution was transferred in Teflon vessels, and they were kept at $150^{\circ} \mathrm{C}$ for 24 hours. Then, the products were filtrated, washed and dried at $50^{\circ} \mathrm{C}$ overnight. The effect of alcohol on $\mathrm{LiFePO}_{4}$ nanosheets microstructures was also investigated.

\section{Evaluation}

The crystal phase of samples was indexed by XRD (UltimaIV, Rigaku Co., Japan). Scans were performed at $2 \theta=10-60^{\circ}$ with scan rate of $4 \%$ min. using $\mathrm{Cu}-\mathrm{Ka}$ radiation. Morphology was observed by FE-SEM (S-4500, Hitachi, Japan) with applied voltage of $15 \mathrm{kV}$. TEM observation was used by JEM-2000FX at $200 \mathrm{kV}$. The composition of the sample was analyzed by ICP (PS-7800, Hitachi Co.). The sample was dissolved in $0.1 \mathrm{M}$ nitric acid, and its solution was measured. The vibrational structure was identified by FT-IR (ALPHA-OPT, Bruker Co.) at wave vector range $400-4000 \mathrm{~cm}^{-1}$. For FT-IR measurements, the sample was grinded with $\mathrm{KBr}$, and the powder was pressed in a mechanical press to form a translucent pellet.

\section{Results and Discussion}

\section{Preparation of layered $\mathrm{NH}_{4} \mathrm{FePO}_{4} \cdot \mathrm{H}_{2} \mathrm{O}$}

$\mathrm{XRD}$ results of the products obtained from $\mathrm{FeSO}_{4}$ solution and $\mathrm{NH}_{4} \mathrm{H}_{2} \mathrm{PO}_{4}$ solution were showed in Figure 1A. The diffraction peaks were attributed to layered $\mathrm{NH}_{4} \mathrm{FePO}_{4} \cdot \mathrm{H}_{2} \mathrm{O}$. The (200) peak at $10^{\circ}$ was depended on layered structure. Figure 1B shows SEM images for

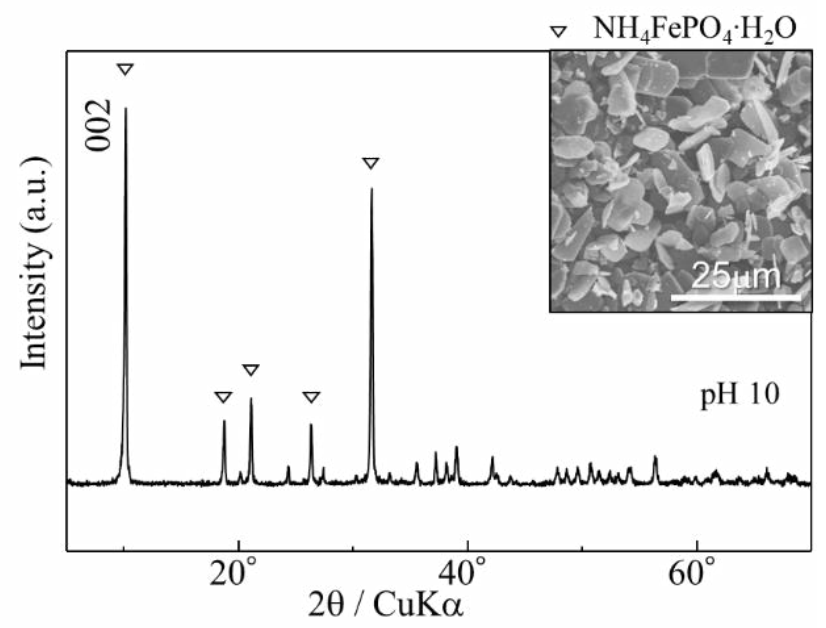

Figure 1: (A) XRD pattern and (B) SEM image of layered $\mathrm{NH}_{4} \mathrm{FePO}_{4} \cdot \mathrm{H}_{2} \mathrm{O}$ sample synthesized at $\mathrm{pH} 10$ in hydrothermal reaction. the obtained products. From SEM observation in Figure 1B, sheetlike particle was observed for samples obtained at $\mathrm{pH} 10$ and it was thought to be layered $\mathrm{NH}_{4} \mathrm{FePO}_{4}$. The particle size was about several ten micrometers on a side, and the thickness was about $200 \mathrm{~nm}$ for layered $\mathrm{NH}_{4} \mathrm{FePO}_{4} \cdot \mathrm{H}_{2} \mathrm{O}$. From ICP analysis for layered $\mathrm{NH}_{4} \mathrm{FePO}_{4} \cdot \mathrm{H}_{2} \mathrm{O}, \mathrm{Fe} / \mathrm{P}$ ratio was 1.02 , and iron concentration in layered $\mathrm{NH}_{4} \mathrm{FePO}_{4}$ was 5 $\mathrm{mmol} / \mathrm{g}$, which was the estimated Li quantity necessary for reaction. Thus, it was found that large layered $\mathrm{NH}_{4} \mathrm{FePO}_{4} \cdot \mathrm{H}_{2} \mathrm{O}$ with several tens $\mu \mathrm{m}$ on a side and about $0.2 \mu \mathrm{m}$ in thickness was obtained.

\section{Synthesis $\mathrm{LiFePO}_{4}$ nanosheets from layered $\mathrm{NH}_{4} \mathrm{FePO}_{4} \cdot \mathrm{H}_{2} \mathrm{O}$ compounds}

Synthesis of $\mathrm{LiFePO}_{4}$ nanosheets by the subsequent hydrothermal process were attempted in $\mathrm{LiCl}$ aqueous solution with a few kinds of concentration from layered $\mathrm{NH}_{4} \mathrm{FePO}_{4} \cdot \mathrm{H}_{2} \mathrm{O}$ as a starting material. The addition of dissolved $\mathrm{LiCl}$ solution was changed from $1 \mathrm{mmol}$ to $20 \mathrm{mmol}$. An XRD result of sample treated by hydrothermal process was showed in Figure 2. With $\mathrm{LiCl}$ addition less than $5 \mathrm{mmol}$, the diffraction peaks were attributed to olivine-type $\mathrm{LiFePO}_{4}$ and in part $\mathrm{NH}_{4} \mathrm{FePO}_{4} \cdot \mathrm{H}_{2} \mathrm{O}$ residue. The peak at $10^{\circ}$ derived from the layered structure was disappeared with increasing $\mathrm{LiCl}$ addition, and single phase of $\mathrm{LiFePO}_{4}$ was obtained in $\mathrm{LiCl}$ solution more than $5 \mathrm{mmol}$. Compared with XRD patterns reported by past report [10], (200) peak of $\mathrm{LiFePO}_{4}$ at $17^{\circ} \mathrm{C}$ was larger for obtained products. It was thought that obtained $\mathrm{LiFePO}_{4}$ was highly oriented. SEM images were showed in Figure 3. In case of products obtained with $1 \mathrm{mmol} \mathrm{LiCl}$ addition, nanosheet-like products derived from $\mathrm{NH}_{4} \mathrm{FePO}_{4} \cdot \mathrm{H}_{2} \mathrm{O}$ was remained and many nano-blocks with some tens nanometer on a side were precipitated on the surface of $\mathrm{NH}_{4} \mathrm{FePO}_{4} \cdot \mathrm{H}_{2} \mathrm{O}$ sheets. With increasing $\mathrm{LiCl}$ addition, the number of nano-blocks tended to increased. Considering XRD results, it was thought that the nano-blocks were corresponding to $\mathrm{LiFePO}_{4}$ phase. A FT-IR spectrum was showed in Figure 4 . Layered $\mathrm{NH}_{4} \mathrm{FePO}_{4} \bullet \mathrm{H}_{2} \mathrm{O}$ has the IR active species, $\mathrm{NH}_{4}^{+}, \mathrm{H}_{2} \mathrm{O}$, and $\mathrm{PO}_{4}^{3-}$. From the spectra of the raw

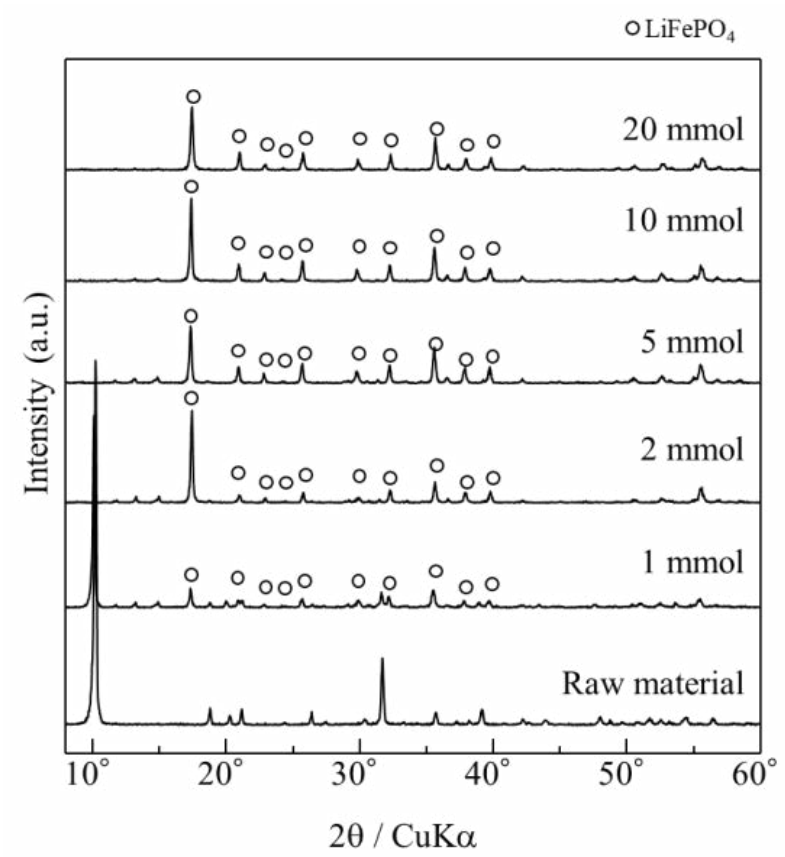

Figure 2: $\mathrm{XRD}$ patterns of $\mathrm{LiFePO}_{4}$ sample synthesized from layered $\mathrm{NH}_{4} \mathrm{FePO}_{4} \cdot \mathrm{H}_{2} \mathrm{O}$ as raw material. 
Citation: Togo M, Nakahira A (2017) Synthesis and Evaluation of Olivine Nanosheets from Layered Ammonium Iron Phosphate Monohydrate. J Material Sci Eng 6: 403. doi: 10.4172/2169-0022.1000403

Page 3 of 4

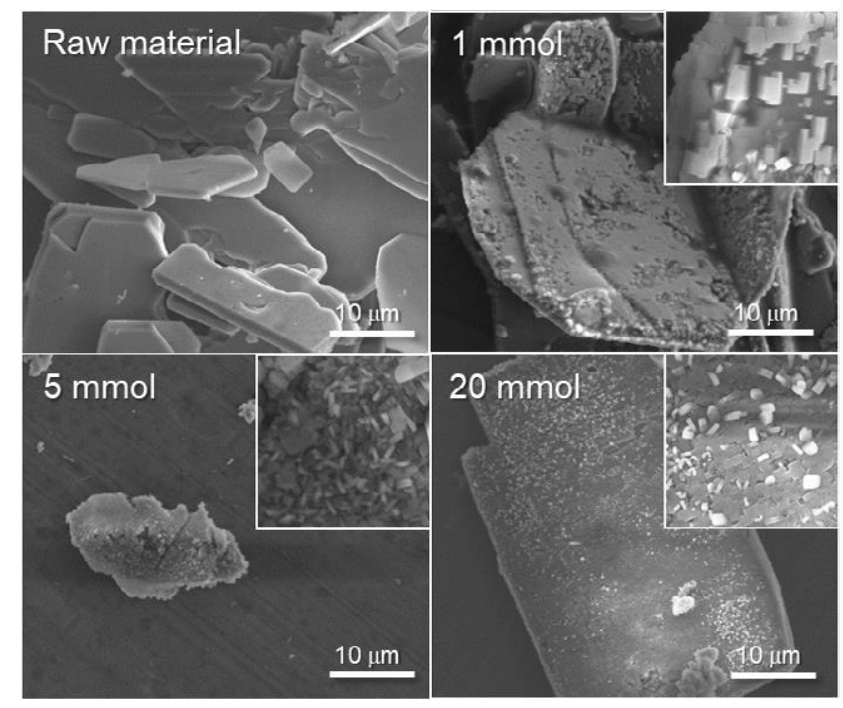

Figure 3: $\mathrm{SEM}$ images of $\mathrm{LiFePO}_{4}$ nanosheets sample synthesized from layered $\mathrm{NH}_{4} \mathrm{FePO}_{4} \cdot \mathrm{H}_{2} \mathrm{O}$ as raw material.

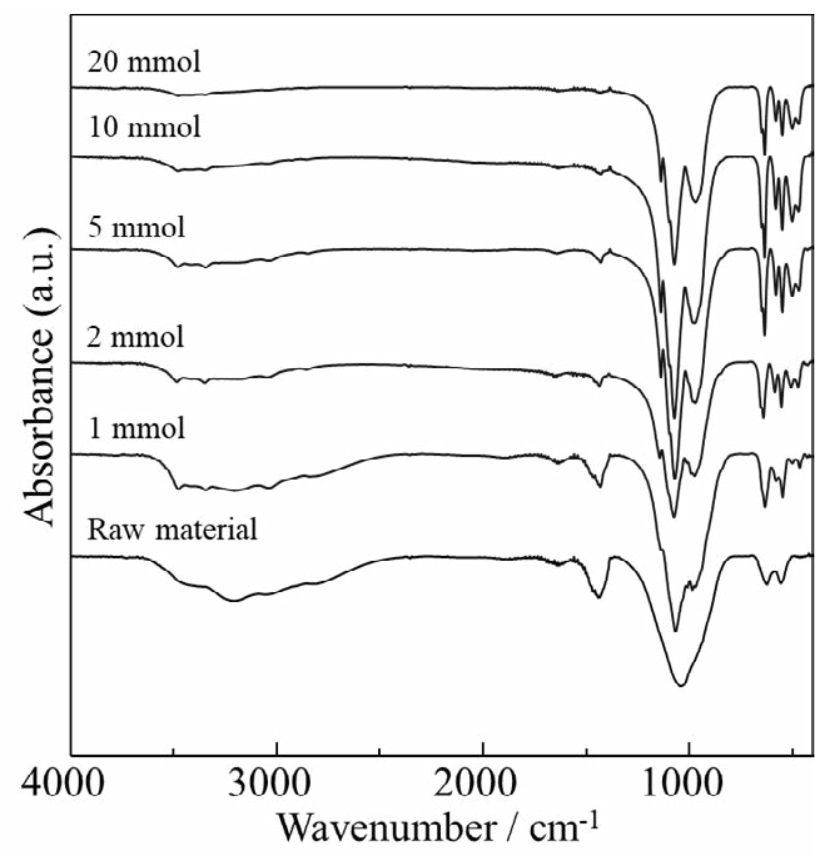

Figure 4: FTIR spectra of $\mathrm{LiFePO}_{4}$ nanosheets sample synthesized from layered $\mathrm{NH}_{4} \mathrm{FePO}_{4} \cdot \mathrm{H}_{2} \mathrm{O}$ as raw material.

material, the broad absorption bands of $\mathrm{H}_{2} \mathrm{O}$ were existed around 3300 $\mathrm{cm}^{-1}$, those of $\mathrm{NH}_{4}^{+}$were at $2400 \mathrm{~cm}^{-1}$, and those of $\mathrm{PO}_{4}^{3-}$ were around $1300-400 \mathrm{~cm}^{-1}$. With increasing $\mathrm{LiCl}$ addition, the absorption bands at $2400 \mathrm{~cm}^{-1}$ and around $3300 \mathrm{~cm}^{-1}$ decreased, and it was showed that $\mathrm{NH}_{4}^{+}$ and $\mathrm{H}_{2} \mathrm{O}$ in interlayer was released. In addition, the absorption bands of $\mathrm{PO}_{4}^{3-}$ were separating and sharpening, and it was thought that $\mathrm{LiFePO}_{4}$ structure was crystalized. Although the reaction mechanism is not cleared yet, it was thought that hydrothermal reaction was progressing from surface of layered $\mathrm{NH}_{4} \mathrm{FePO}_{4} \cdot \mathrm{H}_{2} \mathrm{O}$. From ICP results, $\mathrm{NH}_{4}^{+}$and $\mathrm{H}_{2} \mathrm{O}$ were released from interlayer while reaction from $\mathrm{NH}_{4} \mathrm{FePO}_{4} \cdot \mathrm{H}_{2} \mathrm{O}$ to $\mathrm{LiFePO}_{4}$.

\section{Influence of a kind of solvents for $\mathrm{LiCl}$ solution through the hydrothermal process}

Effect of a kind of solvents for $\mathrm{LiCl}$ solution on the microstructure of products treated by the hydrothermal process was investigated for $\mathrm{LiFePO}_{4}$ nanosheets synthesis. Ethanol and ethylene glycol were used as the solvent for $\mathrm{LiCl}$ solution through the hydrothermal process for $\mathrm{LiFePO}_{4}$ nanosheets. $\mathrm{LiCl}$ was added $5 \mathrm{mmol}$ in ethanol and 10 mmol in ethylene glycol. XRD results of the products in various $\mathrm{LiCl}$ solutions were showed in Figure 5. In the case of ethanol solvents, the diffraction peaks were attributed to olivine-type $\mathrm{LiFePO}_{4}$ and $\mathrm{Li}_{3} \mathrm{PO}_{4}$. It was thought that dissolution of $\mathrm{NH}_{4} \mathrm{FePO}_{4}$ was faster in ethanol, and consequently $\mathrm{Li}_{3} \mathrm{PO}_{4}$ was precipitated in $\mathrm{Li}$ rich condition. In the case of ethylene glycol, the diffraction peaks were attributed to olivinetype $\mathrm{LiFePO}_{4}$. Compared with deionized water solvents, the peaks of obtained $\mathrm{LiFePO}_{4}$ were broad, and the intensity of (200) peak was not high. TEM images and diffraction pattern of $\mathrm{NH}_{4} \mathrm{FePO}_{4} \cdot \mathrm{H}_{2} \mathrm{O}$ as raw material and sample with $\mathrm{LiCl}$ addition in each solvent were showed in Figure 6. About $\mathrm{NH}_{4} \mathrm{FePO}_{4} \bullet \mathrm{H}_{2} \mathrm{O}$, large sheet-like particle was observed, and it was thought to be single crystal from diffraction pattern. Then, the samples with $\mathrm{LiCl}$ addition in deionized water had large sheet-like morphology, and it was composed of arranged nano-blocks. The size of nano-blocks was estimated $100 \mathrm{~nm}$ in width and $180 \mathrm{~nm}$ in length from high magnification images. In addition, diffraction pattern showed a part of samples was oriented. In case of ethanol and ethylene glycol solvents, large sheet-like particles were observed. From high magnification images, the size of nano-block in ethanol was $180 \mathrm{~nm}$ in width and $280 \mathrm{~nm}$ in length, and in ethylene glycol, it was less $50 \mathrm{~nm}$ in width and more $200 \mathrm{~nm}$ in length. In case of ethylene glycol, $\mathrm{LiFePO}_{4}$ nanosheets were composed of thin and long nanoblocks, although samples obtained in ethanol and in deionized water were composed of cubic nano-blocks. However, diffraction pattern of the samples in ethanol and ethylene glycol were spot pattern as same as that of the samples in deionized water, showing the same crystallinity for $\mathrm{LiFePO}_{4}$ nanosheets sample synthesized in the different solvents. It was obvious

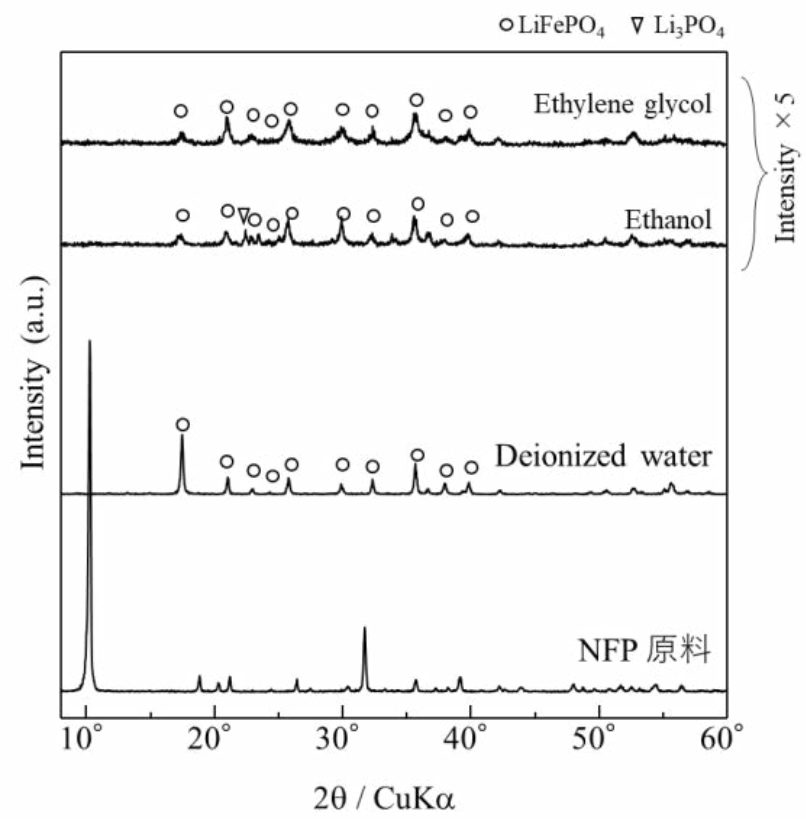

Figure 5: XRD patterns of $\mathrm{LiFePO}_{4}$ nanosheets sample synthesized from layered $\mathrm{NH}_{4} \mathrm{FePO}_{4} \cdot \mathrm{H}_{2} \mathrm{O}$ as raw material in various solvents. 
Citation: Togo M, Nakahira A (2017) Synthesis and Evaluation of Olivine Nanosheets from Layered Ammonium Iron Phosphate Monohydrate. J Material Sci Eng 6: 403. doi: 10.4172/2169-0022.1000403

Page 4 of 4

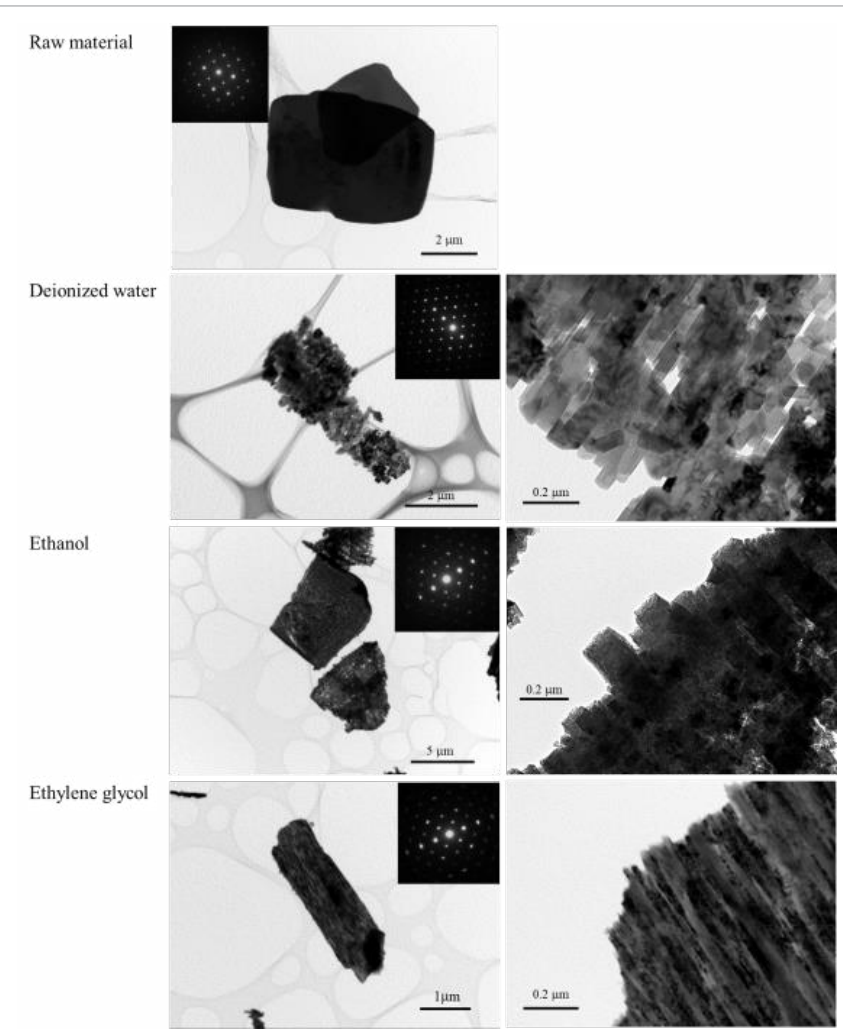

Figure 6: TEM images and diffraction patterns of $\mathrm{LiFePO}_{4}$ nanosheets sample synthesized from layered $\mathrm{NH}_{4} \mathrm{FePO}_{4} \cdot \mathrm{H}_{2} \mathrm{O}$ as raw material in various solvents.

that the microstructure of $\mathrm{LiFePO}_{4}$ nanosheets was dependent on the solvents in $\mathrm{LiCl}$ solution through the hydrothermal process. The detailed analysis of microstructure and growth mechanism is under investigation.

\section{Conclusion}

$\mathrm{NH}_{4} \mathrm{FePO}_{4} \cdot \mathrm{H}_{2} \mathrm{O}$ were prepared by hydrothermal process. Obtained $\mathrm{NH}_{4} \mathrm{FePO}_{4} \cdot \mathrm{H}_{2} \mathrm{O}$ were composed of sheet-like particle with several tens micrometer. And then $\mathrm{LiFePO}_{4}$ nanosheets were synthesized by the subsequent hydrothermal process at $\mathrm{pH} 6$ in various $\mathrm{LiCl}$ solution from layered $\mathrm{NH}_{4} \mathrm{FePO}_{4} \cdot \mathrm{H}_{2} \mathrm{O}$ as a raw material. In deionized water solvent, the morphology of $\mathrm{LiFePO}_{4}$ was large sheets composed of arranged nano-blocks with several hundred nanometers on a side. With $\mathrm{LiCl}$ addition in alcohol solvent, $\mathrm{LiFePO}_{4}$ nanosheets were also composed of nano-blocks, but the shapes of nano-blocks were different. The size of nano-blocks in ethanol was estimated $180 \mathrm{~nm}$ in width and $280 \mathrm{~nm}$ in length as well as ones in deionized water, and the length of nano-blocks in ethylene glycol increased.

\section{Acknowledgment}

We thank for Grant-in-Aid for Scientific Research on Innovative Areas "Nano Informatics" (Grant No. 16H00892) from JSPS.

\section{References}

1. Padhi AK, Nanjundaswamy KS, Goodenough JB (1997) Effect of Structure on the $\mathrm{Fe}^{3+} / \mathrm{Fe}^{2+}$ Redox Couple in Iron Phosphates. Journal of the Electrochemical Society 144: 1609-1613.

2. Wang D, Buqa H, Crouzet M, Deghenghi G, Drezen T, et al. (2009) Highperformance, nano-structured LiMnPO4 synthesized via a polyol method. Journal of Power Sources 189: 624-628.

3. Yamada A, Kudo Y, Liu KY (2001) Phase Diagram of $\mathrm{Li}_{x}\left(\mathrm{Mn}_{\mathrm{y}} \mathrm{Fe}_{1-y}\right) \mathrm{PO}_{4}$ $(0 \leqslant x, y \leqslant 1)$. Journal of the Electrochemical Society 148: A1153-A1158.

4. Li G, Azuma H, Tohda M (2002) Optimized LiMn $\mathrm{Fe}_{1-\mathrm{PO}}$ as the Cathode for Lithium Batteries. Journal of the Electrochemical Society 149: A743-A747.

5. Delacourt C, Laffonta L, Bouchetb R, Wurma C, Lerichea JB, et al. (2005) Toward Understanding of Electrical Limitations (Electronic, Ionic) in LiMPO, $(\mathrm{M}=\mathrm{Fe}, \mathrm{Mn})$ Electrode Materials. Journal of the Electrochemical Society 152 : A913-A921.

6. Morgan D, Van der Ven A, Ceder G (2004) Li Conductivity in $\mathrm{Li}_{x} \mathrm{MPO}_{4}$ $(\mathrm{M}=\mathrm{Mn}, \mathrm{Fe}, \mathrm{Co}, \mathrm{Ni})$ Olivine Materials. Electrochemical and Solid-State Letters 7(2): A30-A32.

7. Chung SY, Blocking JT, Chiang YM (2002) Electronically conductive phosphoolivines as lithium storage electrodes. Nature Materials 1: 123-128.

8. Zaghib K, Mauger A, Gendron F, Julien CM (2008) Surface Effects on the Physical and Electrochemical Properties of Thin LiFePO ${ }_{4}$ Particles. Chemistry of Materials 20: 462-469.

9. Belharouak I, Johnson C, Amine K (2005) Synthesis and electrochemical analysis of vapor-deposited carbon-coated $\mathrm{LiFePO}_{4}$. Electrochemistry Communications 7: 983-988.

10. Yang S, Zavalij PY, Whittingham MS (2001) Hydrothermal synthesis of lithium iron phosphate cathodes. Electrochemistry Communications 3: 505-508.

11. Ni J, Morishita M, Kawabe Y, Watada M, Takeshi N, et al. (2010) Hydrothermal preparation of $\mathrm{LiFePO}_{4}$ nanocrystals mediated by organic acid. Journal of Power Sources 195: 2877-2882.

12. Dokko K, Koizumi S, Nakano H, Kanamura K (2007) Particle morphology, crystal orientation, and electrochemical reactivity of $\mathrm{LiFePO}_{4}$ synthesized by the hydrothermal method at 443K. Journal of Materials Chemistry 17: 48034810 .

13. Delmas C, Maccario M, Croguennec L, Le Cras F, Weil F (2008) Lithium deintercalation in $\mathrm{LiFePO}_{4}$ nanoparticles via a domino-cascade model. Nature Materials 71: 665-671.

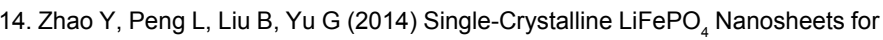
High-Rate Li-lon Batteries. Nano Letters 14(5): 2849-2853.

15. Sasaki T, Watanabe M, Hashizume H, Yamada H, Nakagawa H (1996) Macromolecule-like Aspects for a Colloidal Suspension of an Exfoliated Titanate. Pairwise Association of Nanosheets and Dynamic Reassembling Process Initiated from It. Journal of the American Chemical Society 118: 83298335.

16. Takagaki A, Yoshida T, Lu D, Kondo JN, Hara M, et al. (2004) Titanium Niobate and Titanium Tantalate Nanosheets as Strong Solid Acid Catalysts. The Journal of Physical Chemistry B 108: 11549-11555.

17. Omomo Y, Sasaki T, Wang LZ, Watanabe M (2003) Redoxable Nanosheet Crystallites of $\mathrm{MnO}_{2}$ Derived via Delamination of a Layered Manganese Oxide. Journal of the American Chemical Society 125: 3568-3575. 